\title{
The block to apoptosis in bovine two-cell embryos involves inhibition of caspase-9 activation and caspase-mediated DNA damage
}

\author{
Amber M Brad, Katherine E M Hendricks and Peter J Hansen \\ Department of Animal Sciences, University of Florida, PO Box 110910, Gainesville, Florida 32611-0910, USA \\ Correspondence should be addressed to P J Hansen; Email: hansen@animal.ufl.edu \\ A M Brad is now at Tec Professionals, Lafayette, Indiana, USA
}

\begin{abstract}
The capacity of the preimplantation embryo to undergo apoptosis in response to external stimuli is developmentally regulated. Acquisition of apoptosis does not occur in the cow embryo until between the 8-and 16-cell stages. The purpose of the present experiments was to determine the mechanism by which apoptosis is blocked in the bovine two-cell embryo. Heat shock $\left(41^{\circ} \mathrm{C}\right.$ for $\left.15 \mathrm{~h}\right)$ did not increase activity of caspase-9 or group II caspases (caspase-2, -3, and -7) in two-cell embryos but did in day 5 embryos. Exposure of embryos to carbonyl cyanide 3-chlorophenylhydrazone (CCCP) to depolarize mitochondria resulted in activation of caspase-9 and group II caspases at both stages of development. For day 5 embryos, CCCP also increased the proportion of blastomeres that underwent DNA fragmentation as determined by the TUNEL assay. In contrast, CCCP did not increase TUNEL labeling when applied at the two-cell stage. In conclusion, failure of heat shock to increase caspase-9 and group II caspase activity in the two-cell embryo indicates that the signaling pathway leading to mitochondrial depolarization and caspase activation is inhibited at this stage of development. The fact that CCCP treatment of two-cell embryos induced caspase-9 and group II-caspase activity indicates that caspase activation is possible following mitochondrial depolarization. However, since CCCP did not increase TUNEL labeling of two-cell embryos, actions of group II-caspases to activate DNases is inhibited.
\end{abstract}

Reproduction (2007) 134 789-797

\section{Introduction}

For the preimplantation mammalian embryo, apoptosis can play an important role in determining survival following cellular stress. The best studied example is the bovine embryo produced in vitro. Among the inducers of apoptosis in this organism are elevated temperature (i.e., heat shock; Paula-Lopes \& Hansen 2002a, 2002b, Jousan \& Hansen 2004), arsenic (Krininger et al. 2002), tumor necrosis factor- $\alpha$ (TNF- $\alpha$; Soto et al. 2003, Loureiro et al. 2007), and pro-oxidants (Feugang et al. 2004). The consequences of apoptosis for embryonic survival depend upon its extent. A massive increase in the proportion of blastomeres that become apoptotic is detrimental to embryonic survival. Indeed, use of RNA interference to reduce amounts of the anti-apoptotic protein, survivin, decreased blastocyst development in bovine embryos (Park et al. 2006). However, signals for apoptosis such as exposure to heat shock of $41{ }^{\circ} \mathrm{C}$ or TNF- $\alpha$ cause only about $15-25 \%$ of blastomeres to become apoptotic (Krininger et al. 2002, Paula-Lopes \& Hansen 2002a, 2002b, Soto et al. 2003, Jousan \& Hansen 2004, Loureiro et al. 2007), and this degree of apoptosis is not necessarily deleterious to sustained embryonic development. In fact, TNF- $\alpha$ does not reduce the proportion of embryos that become blastocysts (Soto et al. 2003). For heat shock, limited apoptosis can be an adaptive response that facilitates survival of the embryo after stress. This conclusion is based on observations that inhibition of apoptosis responses using the group II caspase inhibitor z-DEVD-fmk exacerbated the deleterious effects of elevated temperature on development of bovine preimplantation embryos (Paula-Lopes \& Hansen 2002b, Jousan \& Hansen 2007).

Like for other cells, heat shock induces apoptosis in the preimplantation bovine embryo through activation of the mitochondrial or intrinsic pathway. Culture at $41^{\circ} \mathrm{C}$ causes activation of caspase- 9 and caspase- 3 activity (Krininger et al. 2002, Paula-Lopes \& Hansen 2002a, 2002 b, Loureiro et al. 2007). Moreover, induction of TUNEL-positive cells by culture at $41^{\circ} \mathrm{C}$ can be blocked by inhibitors of caspase9 or caspase-3 activity (Paula-Lopes \& Hansen 2002a, Loureiro et al. 2007). TNF- $\alpha$ also utilizes the mitochondrial pathway in the bovine embryo, probably through caspase8-dependent activation of mitochondrial depolarization (Loureiro et al. 2007). 
Induction of apoptosis is a developmentally regulated event. TUNEL-positive cells are first seen in embryos cultured in vitro between the six- and eight-cell stages of development (Matwee et al. 2000, Gjørret et al. 2003). Acquisition of apoptosis responses in response to heat shock first develops around day 4 after insemination, when the embryo is between the 8- and 16-cell stages (Paula-Lopes \& Hansen 2002a). Induction of apoptosis by TNF- $\alpha$ also first occurs in embryos after the eight-cell stage (Soto et al. 2003). The mechanism by which apoptosis is blocked before this stage is not known. Addition of the protein kinase inhibitor staurosporine caused apoptosis in 1- to 16-cell embryos (Matwee et al. 2000), so the biochemical machinery for apoptosis is present in the two-cell embryo. Here, we report results of experiments that indicate that apoptosis in response to heat shock is inhibited in the two-cell embryo at two points in the mitochondrial pathway - caspase-9 activation and caspase-mediated DNA damage.

\section{Results}

\section{Caspase-9 activity following heat shock}

In the first experiment, two-cell and day 5 embryos were cultured at 38.5 or $41.0^{\circ} \mathrm{C}$ for $15 \mathrm{~h}$ and then assayed for caspase-9 activity. Representative fluorescent images of caspase-9 activity from groups of embryos are presented in Fig. 1A-D and the proportion of embryos classified as having high caspase-9 activity is presented in Fig. 1E. There was little detectable caspase- 9 activity in two-cell embryos cultured at either 38.5 or $41^{\circ} \mathrm{C}$ (Fig. $1 \mathrm{~A}$ and C). In contrast, caspase- 9 activity was present in a fraction of day 5 embryos cultured at both temperatures (Fig. 1B and D) and the proportion of embryos classified as having high caspase-9 activity was increased $(P<0.05)$ for embryos cultured at $41^{\circ} \mathrm{C}$ as compared with those cultured at $38.5^{\circ} \mathrm{C}$ (Fig. 1E).

\section{Caspase-9 activity following heat shock and treatment with carbonyl cyanide 3-chlorophenylhydrazone (CCCP)}

Two-cell and day 5 embryos were cultured with and without CCCP for $15 \mathrm{~h}$ at either 38.5 or $41.0^{\circ} \mathrm{C}$. Following culture, embryos were assessed for caspase9 activity. Data are presented in Fig. 2. For embryos cultured with vehicle, results were similar to the previous experiment. There was little caspase activity in two-cell embryos and heat shock did not increase amounts of active caspase-9 (compare Fig. 2A with B). No embryos were classified as having high caspase-9 activity (Fig. 2I). For day 5 embryos, caspase- 9 could be detected in some embryos and the amount of caspase- 9 was greater for embryos at $41^{\circ} \mathrm{C}$ than for embryos at $38.5^{\circ} \mathrm{C}$ (compare Fig. 2C with D). Treatment with CCCP
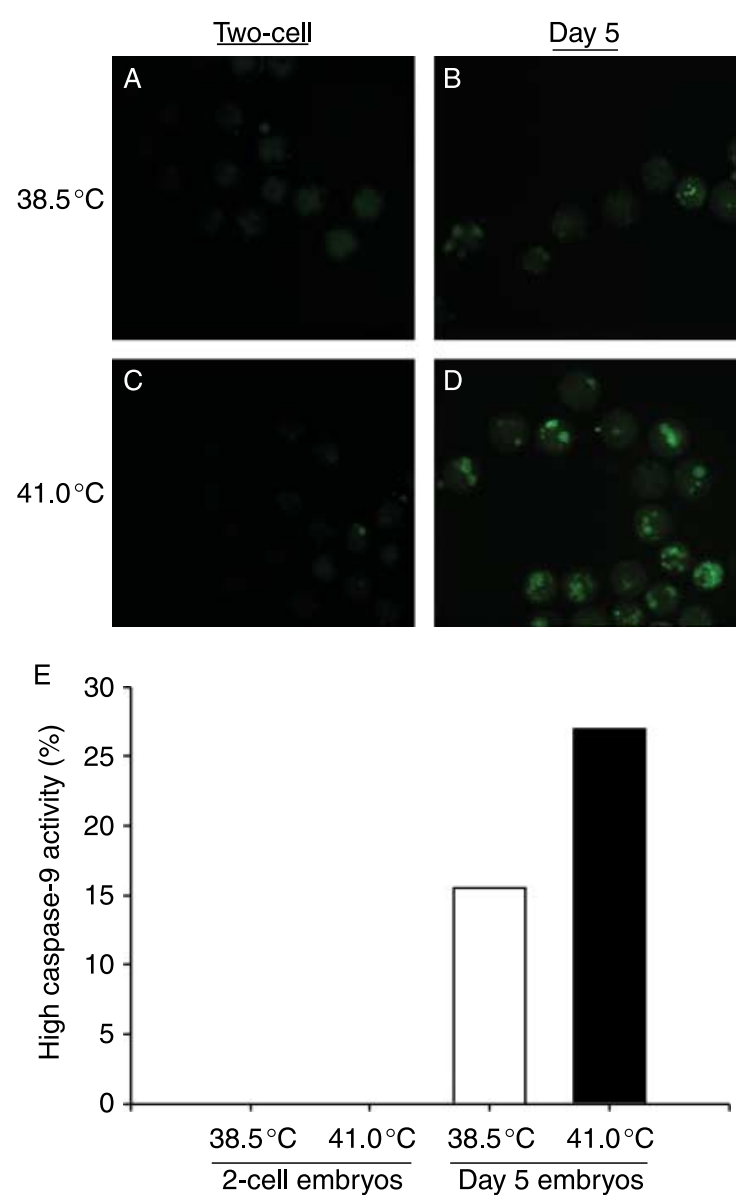

Figure 1 Differential effects of heat shock on caspase- 9 activity in twocell and day 5 bovine embryos. Representative images of caspase- 9 activity are shown for two-cell ( $\mathrm{A}$ and $\mathrm{C}$ ) and day 5 ( $\mathrm{B}$ and $\mathrm{D}$ ) embryos cultured at $38.5^{\circ} \mathrm{C}(\mathrm{A}$ and $\mathrm{B})$ or $41.0^{\circ} \mathrm{C}(\mathrm{C}$ and $\mathrm{D})$ for $15 \mathrm{~h}$ before caspase assay. The lower panel (E) indicates the percentage of embryos classified as exhibiting high caspase-9 activity. Temperature affected the proportion of embryos classified as having high caspase- 9 activity for day 5 embryos only $(P<0.05)$.

to chemically depolarize mitochondria caused a massive change in caspase activity (Fig. 2E-H). In particular, CCCP caused an increase in the proportion of embryos exhibiting caspase- 9 activity as well as in the intensity of caspase-9-dependent fluorescence in individual embryos. The effect of CCCP occurred for both two-cell embryos (Fig. 2E and F) and day 5 embryos (Fig. 2G and $\mathrm{H}$ ) and for embryos cultured at both 38.5 (Fig. 2E and G) and $41.0^{\circ} \mathrm{C}$ (Fig. $2 \mathrm{~F}$ and $\mathrm{H}$ ).

Data on the proportion of embryos classified as having high caspase-9 activity are shown in Fig. 21 for two-cell embryos and Fig. 2J for day 5 embryos. There was a temperature $\times$ treatment interaction $(P<0.001)$ affecting the proportion of embryos with high caspase activity for both two-cell and day 5 embryos. For two-cell embryos, no embryos were classified with high caspase activity in vehicle treatments. Following culture with CCCP, the proportion of embryos with high caspase activity increased 

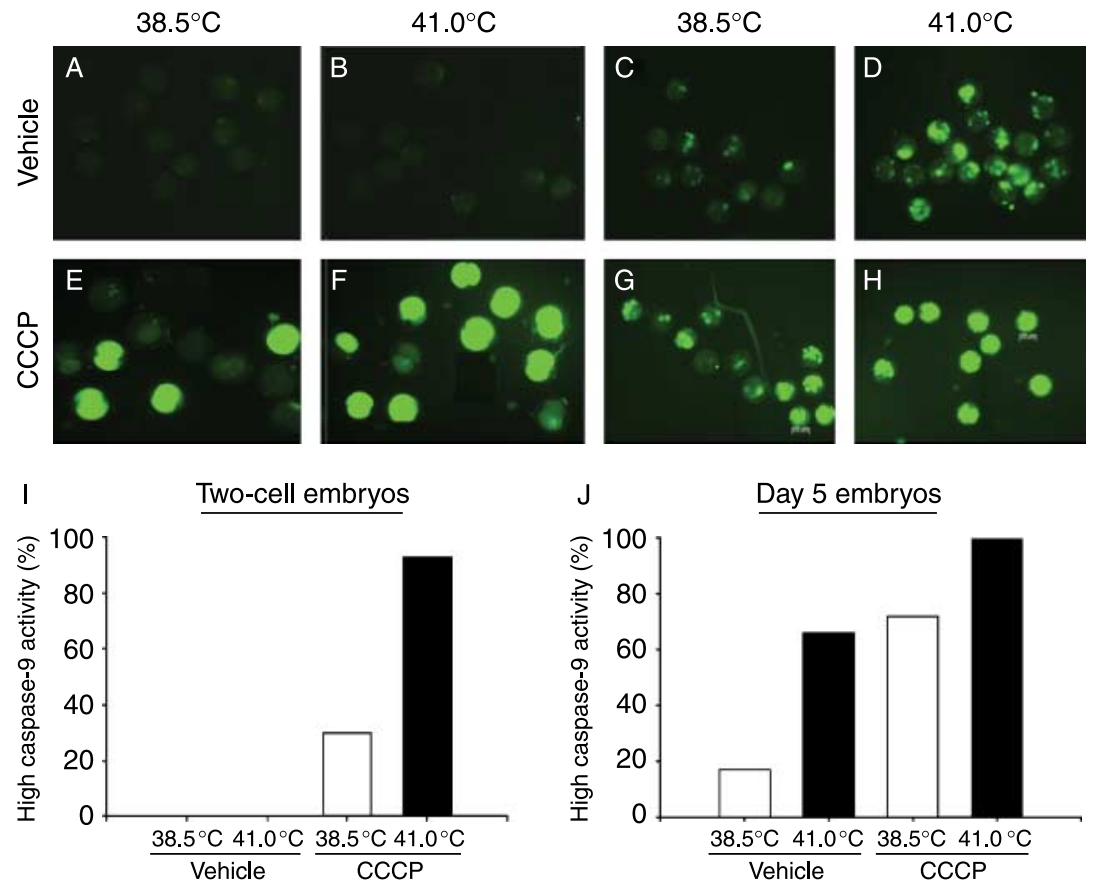

Figure 2 Caspase- 9 activity in two-cell and day 5 ( $\geq 16$ cell) embryos following mitochondrial depolarization with carbonyl cyanide 3-chlorophenylhydrazone (CCCP). Representative images of caspase- 9 activity are shown in the upper panel. Embryos were cultured at $38.5^{\circ} \mathrm{C}(\mathrm{A}, \mathrm{C}, \mathrm{E}$, and G) or $41.0^{\circ} \mathrm{C}(\mathrm{B}, \mathrm{D}, \mathrm{F}$, and $\mathrm{H})$ for $15 \mathrm{~h}$ in either dimethyl sulfoxide (DMSO; A-D) or CCCP (E-H). Data on the percentage of embryos classified with high caspase-9 activity following culture are shown in I (two-cell embryos) and J (day 5 embryos). The percentage was affected by the temperature $\times$ treatment interaction $(P<0.001)$ at both stages of development. to $30 \%$ for embryos at $38.5{ }^{\circ} \mathrm{C}$ and to $93 \%$ for embryos at $41{ }^{\circ} \mathrm{C}$ (Fig. 2I). Thus, CCCP activated caspase-9, and the activation was greater for embryos at $41{ }^{\circ} \mathrm{C}$. For day 5 embryos treated with vehicle, $41^{\circ} \mathrm{C}$ increased the proportion of embryos with high caspase-9 activity as compared with embryos at $38.5{ }^{\circ} \mathrm{C}$ (Fig. 2J). Again, CCCP increased the percentage of embryos classified with high caspase activity at $38.5^{\circ} \mathrm{C}$ and, to a greater extent, at $41^{\circ} \mathrm{C}$.

\section{Group II caspase activity following heat shock and treatment with CCCP}

Two-cell and day 5 embryos were cultured with and without CCCP for $15 \mathrm{~h}$ at 38.5 or $41.0^{\circ} \mathrm{C}$ and then assessed for group II caspase activity using a fluorescent probe that is cleaved by active caspase- $2,-3$, and -7 (Fig. 3). Caspase activity was low in two-cell embryos and heat shock did not increase activity (compare Fig. 3A with B). For day 5 embryos, more embryos had detected group II caspase, especially for embryos cultured at $41{ }^{\circ} \mathrm{C}$ (Fig. 3C and D). As for caspase-9, CCCP treatment increased group II caspase activity in both two-cell embryos and day 5 embryos (Fig. 3E-H).

Quantitative analysis is presented in Fig. $3 \mathrm{I}$ and J. There was a temperature $\times$ treatment interaction $(P<0.001)$ affecting the proportion of embryos with high caspase activity. This was true for both two-cell embryos (Fig. 3l) and day 5 embryos (Fig. 3J). For two-cell embryos, few embryos treated with vehicle had high group II caspase activity, and heat shock at $41^{\circ} \mathrm{C}$ did not increase that proportion. Treatment with CCCP caused a large increase in the proportion of embryos with high group II caspase activity at both 38.5 and $41^{\circ} \mathrm{C}$. For day 5 embryos, culture of vehicle-treated embryos at $41^{\circ} \mathrm{C}$ caused an increase in the proportion of embryos that were classified as having high caspase activity. This increase was smaller, however, than the increase caused by treatment with CCCP. The CCCPinduced increase in caspase II activity was greater for embryos at $41^{\circ} \mathrm{C}$ than for embryos at $38.5^{\circ} \mathrm{C}$.

\section{TUNEL labeling in embryos treated with heat shock and CCCP}

Representative images of TUNEL analysis are shown in Fig. 4A-H and least squares means \pm s.E.M. for the percentage of nuclei positive for the TUNEL reaction and for total cell number are shown in Fig. 4I-K.

Few two-cell embryos contained TUNEL-positive nuclei regardless of treatment group (see Fig. 4A, B, E, and $F$ for representative images and Fig. $4 \mathrm{I}$ for least squares means). Thus, even though CCCP induced caspase-9 and group II caspase activation, it did not result in DNA fragmentation of nuclei in two-cell embryos. Treatment with CCCP did inhibit further development of two-cell embryos as indicated by a reduction in total cell number caused by $\mathrm{CCCP}$ $(P<0.001$; Fig. 4J).

Day 5 embryos responded to both heat shock and CCCP by experiencing an increase in the percentage of nuclei positive for the TUNEL reaction (see Fig. 4C, D, G, and $\mathrm{H}$ for representative images). The percentage of 

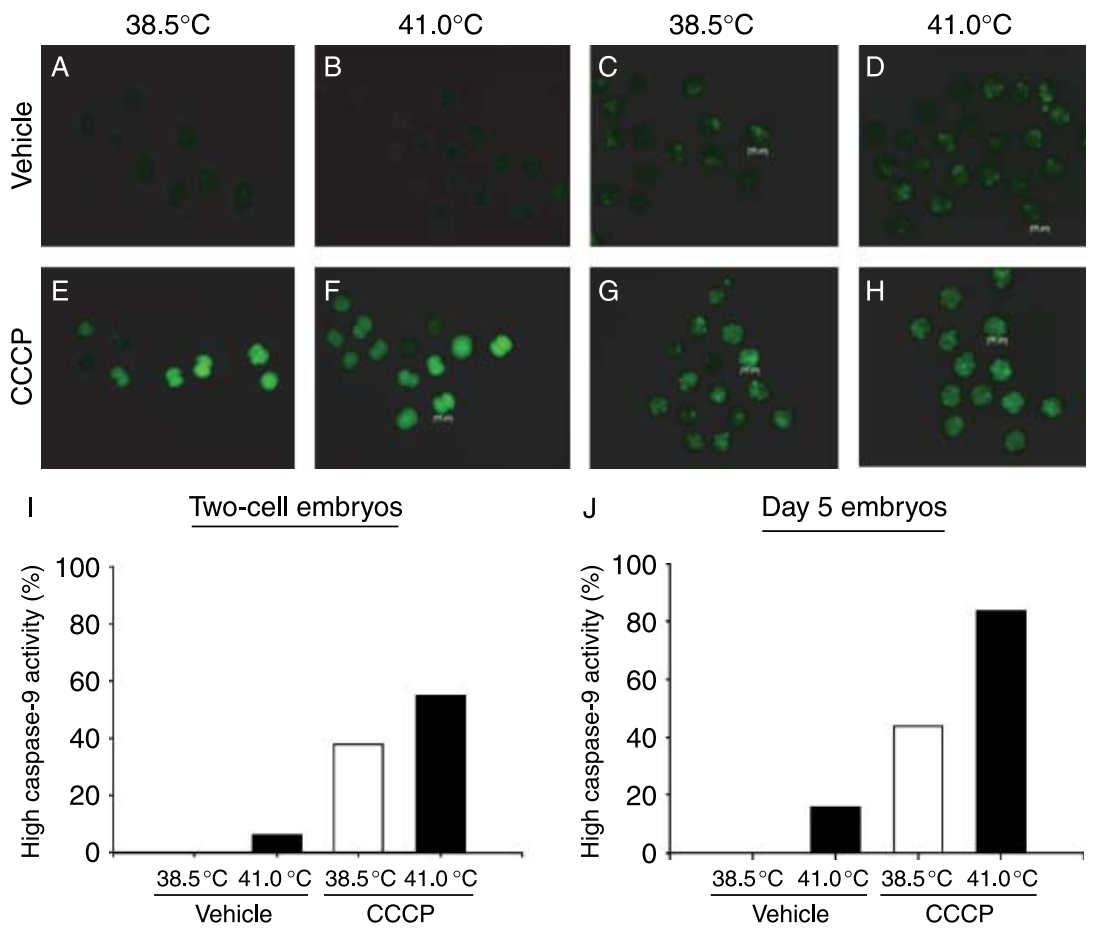

Figure 3 Group II caspase activity in two-cell and day 5 ( $\geq 16$ cell) embryos following mitochondrial depolarization with carbonyl cyanide 3-chlorophenylhydrazone (CCCP). Panels A-H display representative images of group II caspase activity in embryos following culture for $15 \mathrm{~h}$ at $38.5^{\circ} \mathrm{C}(\mathrm{A}, \mathrm{C}$, $\mathrm{E}$, and $\mathrm{G})$ or $41.0^{\circ} \mathrm{C}(\mathrm{B}, \mathrm{D}, \mathrm{F}$, and $\mathrm{H})$ in either dimethyl sulfoxide vehicle (A-D) or CCCP $(E-H)$. Data on the percentage of embryos classified with high group II caspase activity are shown in I (two-cell embryos) and J (day 5 embryos). The percentage was affected by the temperature $\times$ treatment interaction $(P<0.001)$ at both stages of development. The bars on each figure represent $100 \mu \mathrm{m}$. nuclei positive for the TUNEL reaction was affected by a temperature $\times$ treatment interaction $(P<0.01)$. An increase in the percentage of nuclei positive for the TUNEL reaction was caused by culture at $41^{\circ} \mathrm{C}$ and CCCP treatment and the increase caused by $41^{\circ} \mathrm{C}$ was greater for embryos treated with CCCP (Fig. 4K). There was no effect of heat shock or CCCP on total cell number (Fig. 4L).

\section{Discussion}

As for other cells, the pathway for induction of apoptosis by heat shock in the preimplantation bovine embryo involves the mitochondrial pathway. Heat shock increases the activity of caspase-9 and group II caspases (Krininger et al. 2002, Paula-Lopes \& Hansen 2002a, 2002 b, Loureiro et al. 2007), and inhibitors of caspase- 9 and caspase- 3 block induction of TUNEL-positive cells by $41^{\circ} \mathrm{C}$ (Paula-Lopes \& Hansen 2002b, Loureiro et al. 2007). This pathway is inactivated in the earliest stages of development: heat shock first causes increased TUNEL labeling around day 4 after insemination, when the embryo is between the 8- and 16-cell stages (Paula-Lopes \& Hansen 2002a). Using the two-cell embryo as a model, experiments described here indicate that the block to apoptosis occurs at two points in the apoptotic cascade: activation of caspase-9 activity and cleavage of DNA by caspase-3 and other execution caspases. A model illustrating the points in the mitochondrial pathway for apoptosis that are blocked in the two-cell embryo is shown in Fig. 5.
Although heat shock increased caspase-9 activity in day 5 embryos, it had no effect on caspase- 9 activity in the two-cell embryo. This lack of enzyme activity at the two-cell stage does not reflect an absence of the components of the apoptosome in the two-cell embryo. Indeed, artificial depolarization of mitochondria with CCCP resulted in a large increase in caspase- 9 activity. It is possible, however, that mitochondria from the two-cell embryo are deficient in one or more components of the apoptosome and more mitochondrial depolarization is required to activate procaspase- 9 .

Mitochondria may also be resistant to depolarization at the two-cell stage. Some mitochondrial depolarization does occur in the two-cell embryo in response to heat shock. Exposure of two-cell embryos to $41^{\circ} \mathrm{C}$ for $12 \mathrm{~h}$ results in about $7 \%$ of the mitochondria exhibiting a swollen phenotype versus $0.7 \%$ of mitochondria from embryos at $38.5{ }^{\circ} \mathrm{C}$ (Rivera et al. 2003). This degree of depolarization may be too low to lead to caspase-9 activation, especially if some apoptosome components are present in reduced quantity. There is a report using polarity-sensitive dyes that mitochondria are more polarized from the two- to eight-cell stages than afterwards (Tarazona et al. 2006). The drop in polarity between the 8- and 16-cell stages is coincident with acquisition of capacity for heat shock-induced apoptosis (Paula-Lopes \& Hansen 2002a).

Little is known about the developmental changes in the relative abundance of pro-apoptotic and anti-apoptotic members of the $b c l-2$ family in the preimplantation bovine embryo; these changes, if occurring, could 

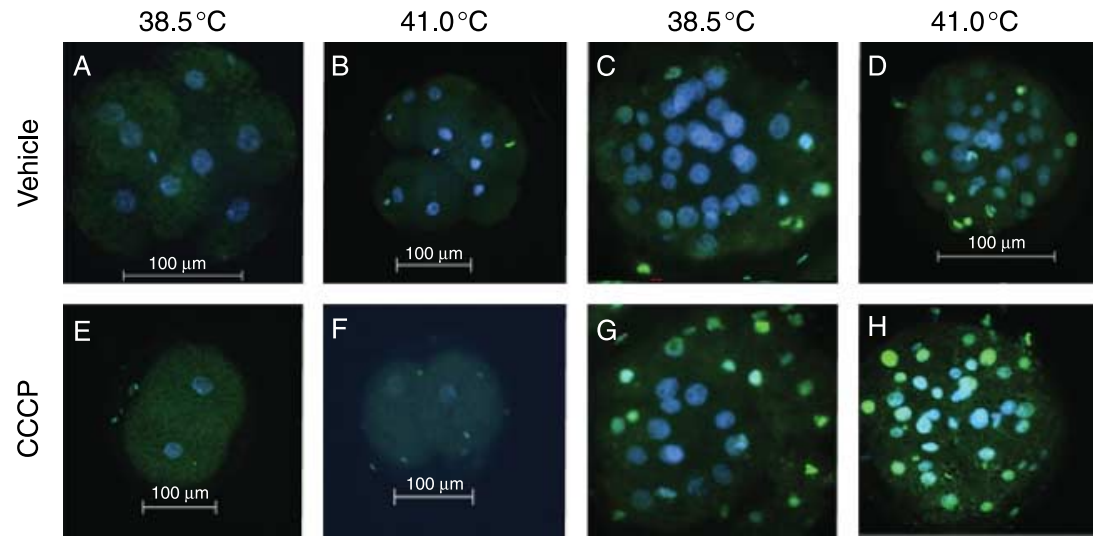

$\underline{\text { Two-cell embryos }}$

I
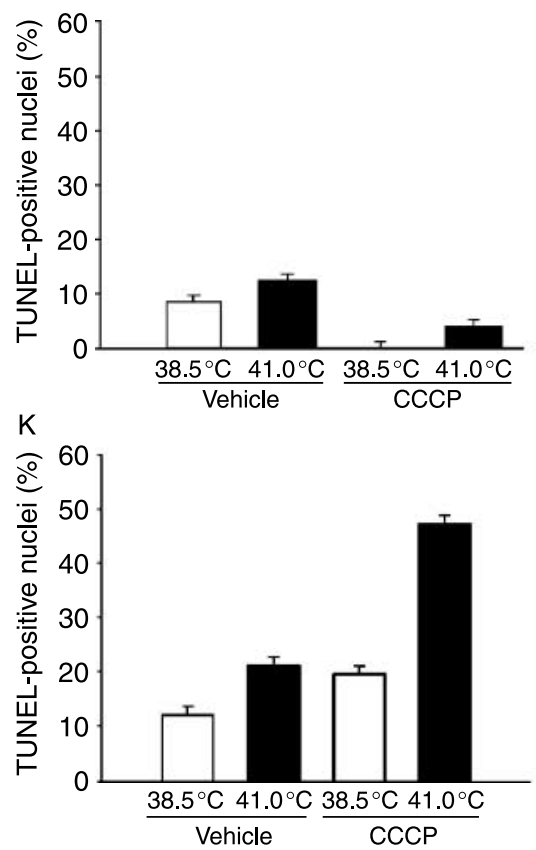
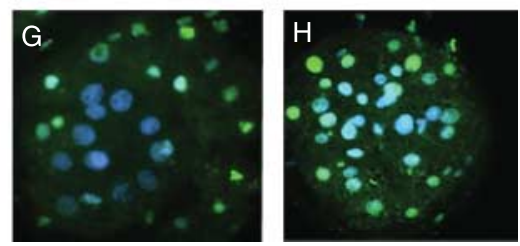

Day 5 embryos

$J$

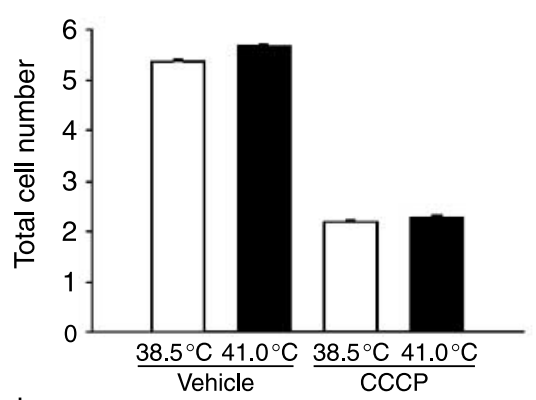

$\mathrm{L}$

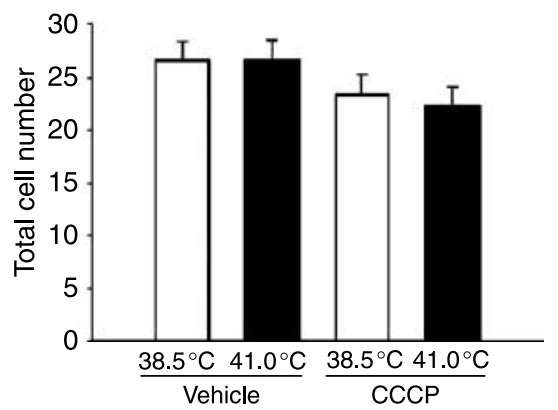

Figure 4 TUNEL labeling of nuclei in two-cell and day 5 ( $\geq 16$ cell) embryos following mitochondrial depolarization with carbonyl cyanide 3-chlorophenylhydrazone (CCCP). Representative images of embryos following the TUNEL procedure are shown in the panels A-H. Nuclei were labeled with Hoechst 33342 and those that are TUNELpositive nuclei are additionally labeled with green fluorescence. Bars in each figure represent $100 \mu \mathrm{m}$. Panels I and J represent least squares means \pm S.E.M. for the percentage of blastomeres that are TUNEL positive (panel I) and cell number (panel J) for embryos treated at the two-cell stage. The percentage of TUNEL-positive cells was not significantly affected by temperature, CCCP, or the interaction. Cell number was reduced by $\mathrm{CCCP}$ treatment $(P<0.001)$. Panels $\mathrm{K}$ and $\mathrm{L}$ represent least squares means \pm S.E.M. for the percentage of blastomeres that are TUNEL positive (panel I) and cell number (panel J) for embryos treated at day 5 . The percentage of TUNEL-positive cells was affected by the temperature $\times$ CCCP interaction $(P<0.01)$ and the cell number was not significantly affected by any treatment. control resistance of mitochondria to depolarizing signals. Transcripts for the pro-apoptotic protein, Bax, were undetectable until the eight-cell stage (Lonergan et al. 2003). In contrast, transcripts for $\mathrm{Bcl}-2$ were abundant in pool of embryos from the two- to eight-cell stages (Yang \& Rajamahendran 2002). These results, based on transcript abundance and not amounts of protein, are consistent with the idea that the membrane of the $\mathrm{Bax} / \mathrm{Bcl}-2$ ratio is less favorable to mitochondrial depolarization early in development.

A key signal for mitochondrial depolarization in response to heat shock is ceramide generated by sphingomyelinase (Chung et al. 2003, Jenkins 2003). Almost nothing is known about the functionality of this signaling system in the preimplantation embryo. It is possible, however, that the two-cell embryo is deficient in the molecules leading to ceramide biosynthesis or in other signaling systems involved in heat shock-induced apoptosis like c-Jun $\mathrm{N}$-terminal kinase (Chung et al. 2003, Hayashi et al. 2004).

Another possibility is that the two-cell embryo has increased amounts of molecules that block caspase-9 activation. One of these, survivin, is present in the preimplantation bovine embryo. However, amounts of survivin are reduced at the two-cell stage (Park et al. 2006) and are unlikely to be a determining factor in the failure of the embryo at this stage of development from undergoing apoptosis. Another inhibitor of caspase-9 activation, $\mathrm{X}$-linked inhibitor of apoptosis, is present at the blastocyst stage of development (Knijn et al. 2005), but it is not known whether it is present in increased amounts early in development.

Failure of caspase- 9 activation is not the only cause for the resistance of the two-cell embryo to undergo 


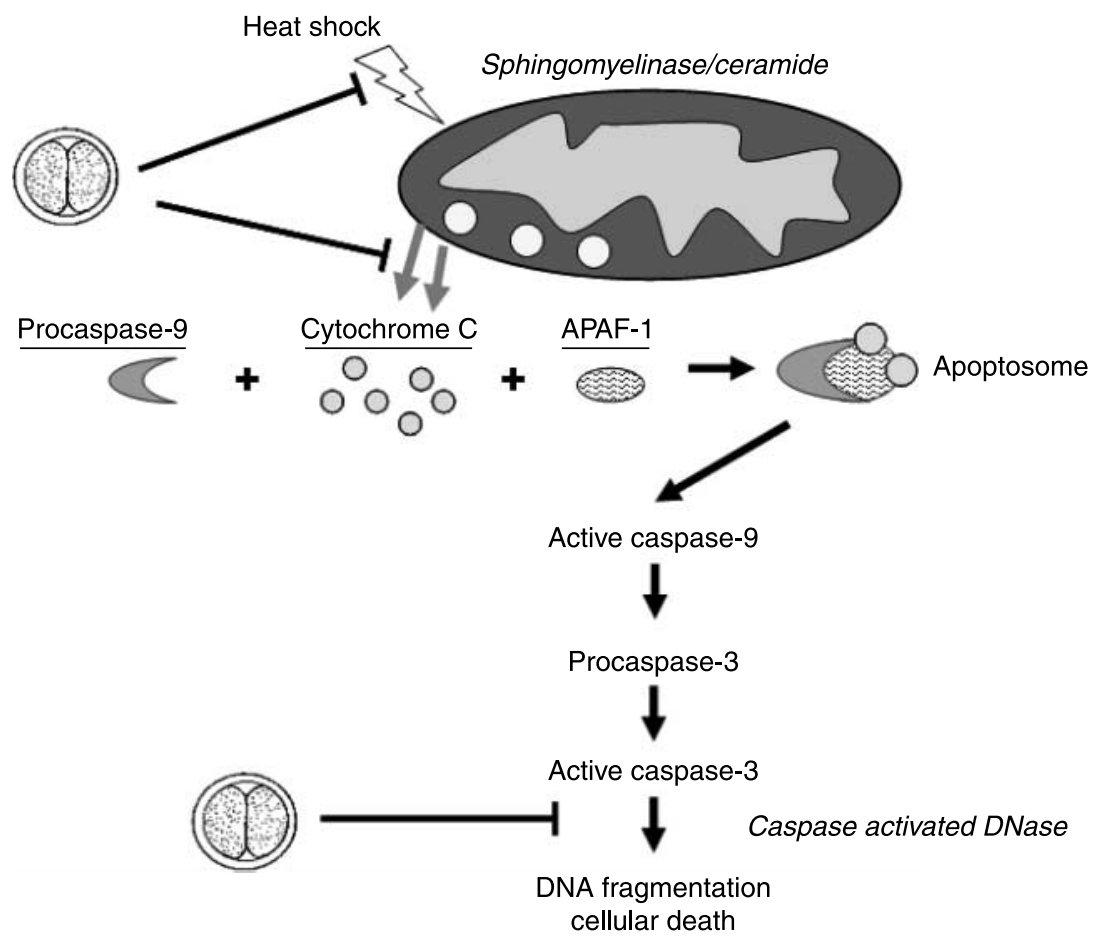

Figure 5 Model describing points in the mitochondrial pathway for apoptosis that are inhibited at the two-cell stage of development in the bovine embryo. Induction of apoptosis by heat shock involves depolarization of the mitochondria. The signal for depolarization is likely to involve the activation of sphingomyelinase to produce the signaling molecule ceramide. Mitochondrial depolarization leads to release of various proapoptotic molecules into the cytoplasm. One of these, cytochrome $c$, forms the apoptosome complex with pro-caspase-9 and APAF-1. Cleavage of procaspase- 9 to form active caspase- 9 results and is followed by activation of caspase- 3 and other execution caspases. Among its actions, caspase-3 cleaves caspase-activated DNase and DNA fragmentation results. This pathway is blocked at two points in the two-cell embryo. First, the embryo's capacity for caspase- 9 activation is blocked, probably because the signal for depolarization is blocked or the mitochondrial membrane is resistant to depolarization. Secondly, activation of caspase-3 does not lead to DNA degradation, either because caspase-activated DNase is limited or inhibited. apoptosis. Indeed, the apoptosis pathway is also inhibited at a point downstream from group II caspase activation. Depolarization of mitochondria with CCCP would be expected to lead to DNA fragmentation because of activation of caspase- 9 and caspase- 3 as well as release of apoptosis-activating factor and endonuclease G from mitochondria (Widlak \& Garrard 2005). Indeed, CCCP caused caspase activation and increased TUNEL labeling in day 5 embryos. In the twocell embryo, in contrast, there was no increased DNA fragmentation in response to CCCP treatment even though caspase- 3 was activated. The concentration of CCCP used was adequate to depolarize mitochondria because caspase- 9 was activated at concentrations of CCCP as low as $1 \mu \mathrm{M}$. The observation that caspase- 9 and caspase- 3 were activated by CCCP in the two-cell embryos leads to the speculation that the two-cell embryo may have a deficiency in caspase-activated DNase (CAD), endonuclease $G$, or the co-factors required for activation of these DNases. One of the co-factors for CAD, histone H1 (Widlak \& Garrard 2005), is present in higher quantities in two-cell embryos than later in development (McGraw et al. 2006). Another co-factor, topoisomerase II, is present throughout early preimplantation development in the mouse (St Pierre et al. 2002). Alternatively, CAD or other components of the process leading to DNA hydrolysis are present in the two-cell embryo but are being actively inhibited by one or more regulatory molecules. This explanation is consistent with the observation that addition of the protein kinase inhibitor staurosporine can induce apoptosis in two-cell embryos (Matwee et al. 2000).

One surprising result was that CCCP was more effective at inducing caspase activation and DNA fragmentation when embryos were cultured at $41{ }^{\circ} \mathrm{C}$ than at $38.5^{\circ} \mathrm{C}$. The most likely explanation for this phenomenon was that integration of CCCP into the cell and mitochondria was amplified at elevated temperature. It is also possible that heat shock-induced changes in mitochondrial polarity enhanced effectiveness of CCCP.

The importance of inhibition of apoptosis responses in the early preimplantation period has not been delineated experimentally. At later stages of development, i.e., at days 4 and 5 after insemination, the capacity for apoptosis can enhance embryonic survival to stress because inhibition of apoptosis responses makes embryos more susceptible to effects of heat shock on development (Paula-Lopes \& Hansen 2002b, Jousan \& Hansen 2007). Perhaps embryos with only a few cells, such as the two- and four-cell embryos, are less able to survive the loss of a cell to apoptosis than larger embryos later in development. Two-cell bovine embryos can develop to the blastocyst stage after bisection (Loskutoff et al. 1993), but loss of both cells by apoptosis would be incompatible with sustained development. Present results indicate that the block to apoptosis that prevents such loss involves inhibition of caspase- 9 activation as well as a loss of capacity for function of apoptosisassociated endonucleases. 


\section{Materials and Methods}

\section{Materials}

Solutions of HEPES-Tyrodes lactate (TL), in vitro fertilization (IVF)$\mathrm{TL}$, and sperm-TL were purchased from Caisson Laboratories (Sugar City, ID, USA) and used to prepare HEPES-Tyrodes albumin lactate pyruvate (TALP), IVF-TALP, and sperm-TALP as previously described (Parrish et al. 1986). Oocyte collection medium was tissue culture medium-199 with Hanks' salts without phenol red (Hyclone, Logan, UT, USA) supplemented with $2 \%(\mathrm{v} / \mathrm{v})$ bovine steer serum (Pel-Freez, Rogers, AR, USA) containing $2 \mathrm{U} / \mathrm{ml}$ heparin, $100 \mathrm{U} / \mathrm{ml}$ penicillin-G, $0.1 \mathrm{mg} / \mathrm{ml}$ streptomycin, and $1 \mathrm{mM}$ glutamine on the day of use. Oocyte maturation medium was tissue culture medium-199 (Invitrogen) with Earle's salts supplemented with $10 \%(\mathrm{v} / \mathrm{v})$ bovine steer serum, $2 \mu \mathrm{g} / \mathrm{ml}$ estradiol $17-\beta, 20 \mu \mathrm{g} / \mathrm{ml}$ bovine follicle-stimulating hormone (Folltropin-V; Vetrepharm Canada, London, ON, Canada), $22 \mu \mathrm{g} / \mathrm{ml}$ sodium pyruvate, $50 \mu \mathrm{g} / \mathrm{ml}$ gentamicin sulfate, and $1 \mathrm{mM}$ glutamine. Percoll was purchased from GE Healthcare (Uppsala, Sweden). Frozen semen from various bulls was donated by Southeastern Semen Services (Wellborn, FL, USA). Potassium simplex optimized medium (KSOM) containing $1 \mathrm{mg} / \mathrm{ml}$ BSA was obtained from Caisson Laboratories. Essentially fatty acid-free BSA was purchased from Sigma. On the day of use, KSOM was modified for bovine embryos to produce KSOM-BE2 as described elsewhere (Soto et al. 2003). CCCP (Sigma) was dissolved in dimethyl sulfoxide (DMSO) to make a $100 \mathrm{mM}$ stock solution. Aliquots were stored at $-20^{\circ} \mathrm{C}$ until the day of use. Stock solutions of CCCP were diluted in KSOM-BE2 for a final concentration of $100 \mu \mathrm{M}$ CCCP in $0.1 \%$ DMSO. An equivalent amount of DMSO was added to KSOM-BE2 for control media.

The In Situ Cell Death Detection Kit (fluorescein) was obtained from Roche Diagnostics Corporation. The Hoechst 33342 dye (Sigma) was used for staining DNA of embryonic cells. The Prolong Antifade Gold Kit was purchased from Promega. Polyvinylpyrrolidone (PVP) was from Eastman Kodak and RQ1 RNase-Free DNase was from Promega. The CaspaLux $9-M_{1} D_{2}$ and PhiPhiLux- $\mathrm{G}_{1} \mathrm{D}_{2}$ assay kits were obtained from Oncolmmunin Inc. (Gaithersburg, MD, USA).

\section{In vitro production of embryos}

In vitro embryo production was performed as previously described (Soto et al. 2003). Briefly, beef and dairy cattle ovaries were obtained from Central Beef Packing Co. (Center Hill, FL, USA). Cumulus-oocyte complexes (COCs) were obtained by slicing 2-10 mm follicles on the surface of ovaries. Complexes with at least three complete layers of compact, intact cumulus cells were washed two times in oocyte collection medium and then matured in groups of ten in $50 \mu$ drops of oocyte maturation medium overlaid with mineral oil (Sigma). Oocytes were matured for $20-22 \mathrm{~h}$ at $38.5^{\circ} \mathrm{C}$ in an atmosphere of $5 \%(\mathrm{v} / \mathrm{v}) \mathrm{CO}_{2}$ in humidified air. Following maturation, COCs were washed once in HEPES-TALPand transferred in groups of 30-40 to four-well plates containing $600 \mu \mathrm{l} \mathrm{IVF-TALP}$ and $25 \mu \mathrm{l}$ of a mixture of $0.5 \mathrm{mM}$ penicillamine, $0.25 \mathrm{mM}$ hypotaurine, and $25 \mu \mathrm{M}$ epinephrine in $0.9 \%(\mathrm{w} / \mathrm{v}) \mathrm{NaCl}$ per well. Oocytes were fertilized by addition of $\sim 1 \times 10^{6}$ Percoll-purified spermatozoa from a pool of frozenthawed semen from three bulls (a different pool of three bulls was used for each replicate). Following co-culture at $38.5^{\circ} \mathrm{C}$ in an atmosphere of $5 \%(\mathrm{v} / \mathrm{v}) \mathrm{CO}_{2}$ in humidified air for 20-22 h, presumptive zygotes were removed from fertilization wells and denuded of cumulus cells by vortex mixing in $1 \mathrm{ml}$ of $1000 \mathrm{U} / \mathrm{ml}$ hyaluronidase in HEPES-TALP. Putative zygotes were placed in groups of 30 in $50 \mu \mathrm{l}$ drops of KSOM-BE2 and cultured at $38.5^{\circ} \mathrm{C}$ in an atmosphere of $5 \%(\mathrm{v} / \mathrm{v}) \mathrm{CO}_{2}$ in humidified air until embryos were selected for treatment at the two-cell stage (30-32 h postinsemination) or at day 5 after insemination. At day 5, only embryos $\geq 16$ cells (i.e., the most advanced embryos in the dish where individual cells could not be visualized) were selected.

\section{Caspase assays}

Embryos were washed three times in $50 \mu$ l drops of pre-warmed HEPES-TALP and then placed in $25 \mu$ drops of HEPES-TALP containing $5 \mu \mathrm{M}$ of either CaspaLux $9-\mathrm{M}_{1} \mathrm{D}_{2}$ (caspase-9 substrate) or PhiPhiLux- $\mathrm{G}_{1} \mathrm{D}_{2}$ (group II caspase specific for caspase-2, -3, and -7 ) at $38.5^{\circ} \mathrm{C}$ for $40 \mathrm{~min}$ in the dark. Negative control embryos were incubated only in HEPES-TALP. Following incubation, embryos were washed four times in $50 \mu$ l HEPESTALP and placed onto two-well slides containing HEPES-TALP. Caspase activity was examined using a Zeiss Axioplan microscope (Zeiss, Göttingen, Germany). AxioVision software and an AxioCam MRm digital camera (Zeiss) were used to acquire images of embryos. Embryos were classified based on the fluorescence intensity as low (none or a few fluorescent cells), medium (less than half of the cells fluorescent), or high (more than half of the cells fluorescent) caspase activity.

\section{TUNEL labeling}

DNA fragmentation was determined by means of terminal deoxynucleotidyl TUNEL. Immediately following the caspase assay, embryos were washed in $50 \mu \mathrm{l}$ of $10 \mathrm{mM} \mathrm{KPO}_{4}(\mathrm{pH} 7.4)$ containing $0.9 \%(\mathrm{w} / \mathrm{v}) \mathrm{NaCl}(\mathrm{PBS})$ and $1 \mathrm{mg} / \mathrm{ml}$ PVP (PBS-PVP). Embryos were fixed in $4 \%(\mathrm{w} / \mathrm{v})$ paraformaldehyde in PBS for $10 \mathrm{~min}$ at room temperature. Embryos were stored in PBS-PVP and stored at $4{ }^{\circ} \mathrm{C}$ until the time of TUNEL assay. The procedure for performing the TUNEL assay was described elsewhere (Roth \& Hansen 2004).

\section{Experiments}

Caspase-9 activity in heat shocked two-cell and day 5 ( $\geq 16$ cell) embryos

Two-cell embryos were selected 30-32 h after insemination and embryos that were $\geq 16$ cells were selected at day 5 after insemination. Embryos were placed into fresh drops of KSOMBE2 (up to 30 embryos per drop) and cultured at 38.5 or $41.0^{\circ} \mathrm{C}$ for $15 \mathrm{~h}$. A heat shock of $41.0^{\circ} \mathrm{C}$ for $15 \mathrm{~h}$ was chosen because this stress consistently induces apoptosis in a fraction of the blastomeres of day 5 embryos (Jousan \& Hansen 2007, Loureiro et al. 2007). Immediately following culture, the caspase-9 assay was performed on embryos as previously described. The experiment was replicated three times using a total of 134 twocell embryos (67 embryos/group) and a total of 151, day 5 embryos (70-81 embryos/group). 
Caspase-9 activity in two-cell and day 5 embryos following mitochondrial depolarization with CCCP

Two-cell and day 5 embryos ( $\geq 16$-cells) were harvested and placed into fresh drops of KSOM-BE2 containing either $0.1 \%$ DMSO (as vehicle) or $100 \mu \mathrm{M}$ CCCP (a protonophore that depolarizes mitochondria; Terada 1981). In a pilot experiment, a similar degree of caspase-9 activation in two-cell embryos occurred at 1, 10, 100, and $200 \mu \mathrm{M}$. Embryos were cultured at 38.5 or $41.0{ }^{\circ} \mathrm{C}$ for $15 \mathrm{~h}$ and then subjected to the caspase- 9 assay immediately afterwards. A total of four replicates were completed for two-cell embryos using 170 embryos (41-44 embryos/group). For day 5 embryos, the experiment was replicated two times using 139 embryos (33-36 embryos/group).

Group II caspase activity in two-cell and day 5 embryos following mitochondrial depolarization with CCСP

This experiment was conducted as described in the previous paragraph except that group II caspase activity was measured following $15 \mathrm{~h}$ culture at 38.5 or $41.0^{\circ} \mathrm{C}$. Immediately following culture, the group II caspase assay was performed as previously described. For caspase assay, the experiment was replicated five times for two-cell embryos using a total of 255 embryos (63-65 embryos/group). The experiment was replicated four times for day 5 embryos using a total of 217 embryos (54-55 embryos/group).

\section{TUNEL labeling in two-cell and day 5 embryos following mitochondrial depolarization with CCCP}

Following caspase assay, embryos described above were fixed in $4 \%(\mathrm{w} / \mathrm{v})$ paraformaldehyde and analyzed using the TUNEL assay to determine the number of apoptotic nuclei. For two-cell embryos, the TUNEL assay was performed using five replicates for a total of 182 embryos ( $n=43-48$ embryos/treatment). For day 5 embryos, the TUNEL assay was performed using six replicates and 315 total embryos $(n=78-79$ embryos per treatment).

\section{Statistical analysis}

Data on the percentage of cells that were TUNEL positive were analyzed by least squares ANOVA using the general linear models procedure of SAS (SAS for Windows, Version 9.0, Cary, NC, USA). Percentage data were transformed by arcsin transformation before analysis. The mathematical model included main effects and all interactions. For example, an experiment with main effects of replicate, temperature, and CCCP $( \pm)$ used a mathematical model with effects of temperature, $\mathrm{CCCP}$, temperature $\triangle \mathrm{CCCP}$, replicate, replicate $\times$ temperature, and replicate $\times$ CCCP. Replicate was considered as a random effect and other main effects were considered fixed. Tests of significance were made using error terms determined by the calculation of expected mean squares. All values reported are least squares means \pm s.E.M. Probability values for the percentage data are based on analysis of arcsintransformed data, while least squares means are from analysis of untransformed data. Categorical data regarding the percentage of embryos classified as having low, medium, or high caspase activity were analyzed by the CATMOD procedure of SAS using the effects of temperature, CCCP treatment, and the interaction.

\section{Acknowledgements}

The authors wish to thank William Rembert for collection of ovaries, Marshall, Adam, and Alex Chernin and the employees of Central Beef Packing Co. (Center Hill, FL, USA) for providing ovaries, and Scott A. Randell (Southeastern Semen Services, Wellborn, FL, USA) for donation of semen. Research was supported in part by Research Grant Award no. US-3551-04 from BARD, the United States-Israel Binational Agricultural Research and Development Fund and Grant no. 2004-3413514715 from the US Department of Agriculture T-STAR. The authors declare that there is no conflict of interest that would prejudice the impartiality of this scientific work.

\section{References}

Chung HS, Park SR, Choi EK, Park HJ, Griffin RJ, Song CW \& Park H 2003 Role of sphingomyelin-MAPKs pathway in heat-induced apoptosis. Experimental and Molecular Medicine 35 181-188.

Feugang JM, de Roover R, Moens A, Léonard S, Dessy F \& Donnay I 2004 Addition of $\beta$-mercaptoethanol or Trolox at the morula/blastocyst stage improves the quality of bovine blastocysts and prevents induction of apoptosis and degeneration by prooxidant agents. Theriogenology 61 71-90.

Gjørret JO, Knijn HM, Dieleman SJ, Avery B, Larsson LI \& MaddoxHyttel P 2003 Chronology of apoptosis in bovine embryos produced in vivo and in vitro. Biology of Reproduction 69 1193-1200.

Hayashi M, Hamasu T, Endoh D, Kawana A, Matsumoto M \& Okui T 2004 High sensitivity of fibroblast cell lines derived from LEC rats to heat treatment. Journal of Veterinary Medical Science 66 1177-1182.

Jenkins GM 2003 The emerging role for sphingolipids in the eukaryotic heat shock response. Cellular and Molecular Life Sciences 60 701-710.

Jousan FD \& Hansen PJ 2004 Insulin-like growth factor-I as a survival factor for the bovine preimplantation embryo exposed to heat shock. Biology of Reproduction 71 1665-1670.

Jousan FD \& Hansen PJ 2007 Insulin-like growth factor-I promotes resistance of bovine preimplantation embryos to heat shock through actions independent of its anti-apoptotic actions requiring PI3K signaling. Molecular Reproduction and Development 74 189-196.

Knijn HM, Wrenzycki C, Hendriksen PJ, Vos PL, Zeinstra EC, van der Weijden GC, Niemann H \& Dieleman SJ 2005 In vitro and in vivo culture effects on mRNA expression of genes involved in metabolism and apoptosis in bovine embryos. Reproduction, Fertility, and Development 17 775-784.

Krininger CE III, Stephens SH \& Hansen PJ 2002 Developmental changes in inhibitory effects of arsenic and heat shock on growth of preimplantation bovine embryos. Molecular Reproduction and Development 63 335-340.

Lonergan P, Rizos D, Gutierrez-Adan A, Moreira PM, Pintado B, de la Fuente J \& Boland MP 2003 Temporal divergence in the pattern of messenger RNA expression in bovine embryos cultured from the zygote to blastocyst stage in vitro or in vivo. Biology of Reproduction 69 1424-1431.

Loskutoff NM, Johnson WH \& Betteridge KJ 1993 The developmental competence of bovine embryos with reduced cell numbers. Theriogenology 39 95-107.

Loureiro B, Brad AM \& Hansen PJ 2007 Heat shock and tumor necrosis factor- $\alpha$ induce apoptosis in bovine preimplantation embryos through a caspase-9 dependent mechanism. Reproduction 133 1129-1137.

Matwee C, Betts DH \& King WA 2000 Apoptosis in the early bovine embryo. Zygote 8 57-68. 
McGraw S, Vigneault C, Tremblay K \& Sirard MA 2006 Characterization of linker histone H1FOO during bovine in vitro embryo development. Molecular Reproduction and Development 73 692-699.

Park SY, Kim EY, Jeon K, Cui XS, Lee WD, Kim NH, Park SP \& Lim JH 2006 Survivin acts as anti-apoptotic factor during the development of bovine pre-implantation embryos. Molecular Reproduction and Development 74 582-590.

Parrish JJ, Susko-Parrish JL, Critser ES, Eyestone WH \& First NL 1986 Bovine in vitro fertilization with frozen-thawed semen. Theriogenology 25 591-600.

Paula-Lopes FF \& Hansen PJ 2002a Heat-shock induced apoptosis in preimplantation bovine embryos is a developmentally-regulated phenomenon. Biology of Reproduction 66 169-177.

Paula-Lopes FF \& Hansen PJ 2002b Apoptosis is an adaptive response in bovine preimplantation embryos that facilitates survival after heat shock. Biochemical and Biophysical Research Communications 295 $37-42$.

St Pierre J, Wright DJ, Rowe TC \& Wright SJ 2002 DNA topoisomerase II distribution in mouse preimplantation embryos. Molecular Reproduction and Development 61 335-346.

Rivera RM, Kelley KL, Erdos GW \& Hansen PJ 2003 Alterations in ultrastructural morphology of two-cell bovine embryos produced in vitro and in vivo following a physiologically-relevant heat shock. Biology of Reproduction 69 2068-2077.
Roth Z \& Hansen PJ 2004 Involvement of apoptosis in disruption of developmental competence of bovine oocytes by heat shock during maturation. Biology of Reproduction 71 1898-1906.

Soto P, Natzke RP \& Hansen PJ 2003 Actions of tumor necrosis factor- $\alpha$ on oocyte maturation and embryonic development in cattle. American Journal of Reproductive Immunology 50 380-388.

Tarazona AM, Rodriguez JI, Restrepo LF \& Olivera-Angel M 2006 Mitochondrial activity, distribution and segregation in bovine oocytes and in embryos produced in vitro. Reproduction in Domestic Animals 41 5-11.

Terada H 1981 The interaction of highly active uncouplers with mitochondria. Biochimica et Biophysica Acta 639 225-242.

Widlak P \& Garrard WT 2005 Discovery, regulation, and action of the major apoptotic nucleases DFF40/CAD and endonuclease G. Journal of Cellular Biochemistry 94 1078-1087.

Yang MY \& Rajamahendran R 2002 Expression of Bcl-2 and Bax proteins in relation to quality of bovine oocytes and embryos produced in vitro. Animal Reproduction Science 70 159-169.

Received 27 March 2007

First decision 9 May 2007

Revised manuscript received 8 August 2007

Accepted 11 September 2007 